\title{
MANUEL VIEGAS GUERREIRO: EVOCAÇÃO DE UM MESTRE E AMIGO
}

\author{
Maria Lucinda Fonseca ${ }^{1}$ \\ Francisco Melo Ferreira ${ }^{2}$
}

Em 1 de Maio de 1997, faleceu, com 84 anos, o Professor Manuel Viegas Guerreiro. A evocação que dele aqui fazemos, simboliza, antes de tudo, uma homenagem a uma figura ímpar da cultura portuguesa deste século - professor e cientista que dedicou toda a vida ao estudo do Homem, na sua acepção mais universal.

Nascido em Querença, concelho de Loulé, em 1 de Novembro de 1912, Manuel Viegas Guereiro foi profundamente marcado pela sua origem popular e algarvia. Como ele próprio repetidamente afirmava, o convívio na infầncia e juventude com a gente simples dos campos do seu querido Algarve, foi a Escola onde adquiriu, quase sem dar por isso, a extraordinária capacidade de comunicação e comunhão com outros homens, independentemente dos contextos geográficos, culturais e sociais em que os encontrasse.

Ainda na infância, Manuel Viegas Guerreiro foi viver com a família para Portimão onde permaneceu até iniciar os seus estudos secundários em Faro. Concluído o curso complementar do liceu, o jovem Manuel Guerreiro muda-se para Lisboa e começa a frequentar as aulas de Filologia Clássica da Faculdade de Letras, concluindo a respectiva licenciatura em 1936, com uma dissertação intitulada "A adivinhação na primitiva epopeia grega e na Eneida. Subsídios".

A vinda para Lisboa e a entrada na Universidade permitem-lhe conhecer e conviver com mestres como Rodrigues Lapa e Leite de Vasconcellos e iniciar uma sólida amizade com vultos como Orlando Ribeiro, seu colega de Faculdade, e, mais tarde, com Agostinho da Silva.

Com Orlando Ribeiro, passa a frequentar assiduamente a casa de Leite de Vasconcellos, o Mestre que viria a marcar decisivamente parte significativa da sua obra.

1 Professora Associada da Faculdade de Letras da Universidade de Lisboa. Investigadora de Centro de Estudos Geográficos, Faculdade de Letras, Cidade Universitária 1699 Lisboa Codex. Tel.: (351-1) 7937997; Fax: (351-1) 7938690. e-mail: 1fonseca@reitoria.ul.pt

2 Investigador no Centro de Tradições Populares Portuguesas "Prof. Manuel Viegas Guerreiro". Faculdade de Letras, Cidade Universitária 1699 Lisboa Codex. Tel.: (351-1) 7920000; Fax: (351-1) 7960063. e-mail: francisco.ferreira@dapp.min-edu.pt 
O início dos anos quarenta marca nova etapa no percurso profissional e científico de Manuel Viegas Guerreiro: já professor efectivo, de português e de latim, iniciou a sua carreira de etnógrafo, começando a auxiliar o Dr. Leite de Vasconcellos no seu labor literário.

Alguns anos após a morte de Leite de Vasconcellos, inconformado com a falta de liberdade e a opressão do regime de Salazar, começa a nascer nele a vontade de abondonar o país. Em 1946 escreveu ao seu amigo Agostinho da Silva, exilado no Uruguai, pedindo-lhe informações sobre as possibilidades de trabalho e as condições de liberdade na América Latina. Respondeu-lhe este: "Vou agora ao assunto principal. Pode-se ser aqui na América professor ou guarda-livros. Ganhos: mais ou menos o mesmo que aí; possibilidade de cultura: mais ou menos o mesmo que aí; liberdade: aqui muito maior; no Brasil um pouco maior; na Argentina, por exemplo, tanta como aí. Mas a minha opinião é a seguinte: não vale a pena emigrar para se ser o mesmo que era aí".

A vontade de mudança e de descoberta de outros povos e culturas, materializa-se um pouco mais tarde na possibilidade de aproveitar a situação de "professor permutante", trocando, entre Setembro de 1948 e Setembro de 1950, o seu lugar no liceu de Faro por outro no Diogo Cão, em Sá da Bandeira.

Depois de um longo período em que foi professor do liceu, em diversos pontos do país, regressa à Faculdade de Letras onde, através da acção do Professor Orlando Ribeiro, que acabara de criar o Centro de Estudos Geográficos, lhe é atribuída, de 1955 a 1970, uma bolsa do Instituto de Alta Cultura. Retomou então o contacto com a obra leitiana, dirigindo a organização e publicação dos manuscritos do Mestre. Os frutos desta sua actividade materializaram-se numa sucessão de obras de referência onde se incluem Contos Populares Portugueses (1955) e Romanceiro Português (1958), e na publicação da monumental Etnografia Portuguesa, cujo $4^{\circ}$ volume (1958) redigiu quase por completo, a partir dos materiais leitianos e de outros por ele próprio recolhidos. Os restantes volumes póstumos, até ao $10^{\circ}$ (1988), foram também organizados e parcialmente escritos por Manuel Viegas Guerreiro com a colaboração de Paulo Soromenho e sua mulher, Alda Soromenho.

Em 1957, por proposta de Jorge Dias, foi nomeado assistente da Missão de Estudos das Minorias Étnicas do Ultramar Português da Junta de Investigação do Ultramar, tendo sido promovido a adjunto do chefe da Missão, em 1959.

Durante vários anos os seus estudos etnográficos vão dedicar-se essencialmente aos Macondes de Moçambique e aos Bochimanes do Sul de Angola, originando diversas publicações de entre as quais merecem especial referência duas obras essenciais dos estudos africanos: Os Macondes de Moçambique: Sabedoria, Lingua, Literatura e Jogos (Vol. IV, 1966) e a sua dissertação de doutoramento, em Etnologia - Bochimanes !Khu de Angola (1968), defendida, na Faculdade de Letras da Universidade de Lisboa, em 7 de Junho de 1969 e tendo obtido a classificação de 19 valores.

O doutoramento inicia uma nova fase na carreira docente e de investigação de Manuel Viegas Guerreiro. Troca definitivamente o liceu pela universidade, passando a exercer as funções de professor das disciplinas de Etnologia Geral e Etnologia Regional, do curso de Geografia da Faculdade de Letras de Lisboa. 


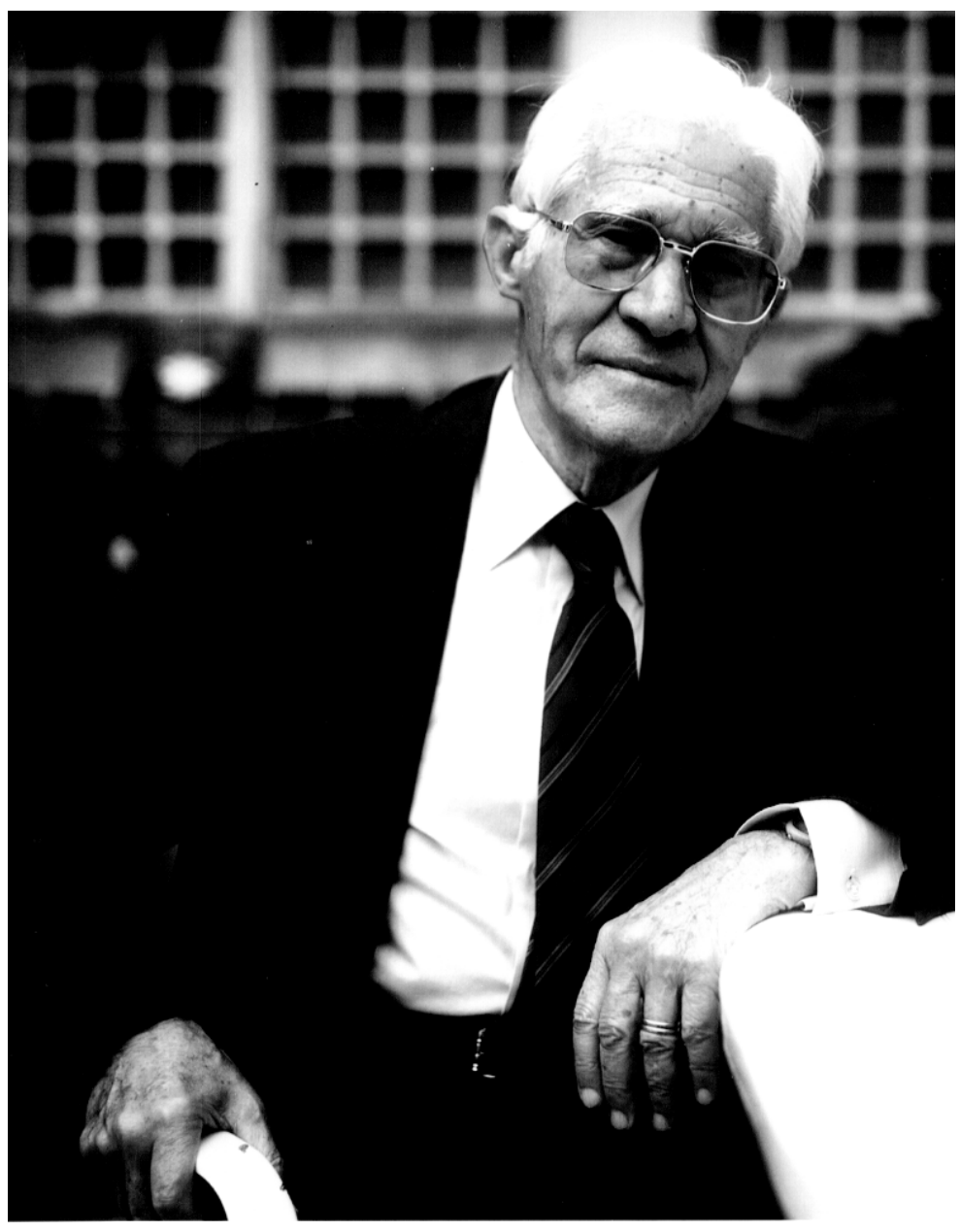

Outro momento fundamental da vida científica de Manuel Viegas Guerreiro coincide com a criação, em 1973, no Centro de Estudos Geográficos (do antigo Instituto Nacional de Investigação Cientifica), de uma linha de Acção de "Recolha e Estudos de Literatura Popular Portuguesa”.

O Professor vive intensamente a revolução de Abril e, com entusiasmo juvenil, organiza com Michel Giacometti, o Programa Trabalho e Cultura do Serviço Cívico Estudantil, cujas recolhas viriam a enriquecer o património da sua linha de Acção no Centro de Estudos Geográficos e a construir parte do importante espólio do museu "O Trabalho" de Setúbal. No mesmo período publicou o Guia de Recolha de Literatura Popular (1976).

Em 1981, inconformado com a burocracia e o ambiente de intriga que invade as 
universidades, pede a aposentação. Retirado do ensino, continua a frequentar diariamente a Faculdade de Letras e a prosseguir a sua investigação em múltiplas áreas de pesquisa e a publicar intensamente. Entre as obras mais importantes dessa época, salienta-se a monografia etnográfica sobre Pitões das Júnias.

Uma outra vertente do seu trabalho relaciona-se com descrições dos primeiros contactos com o Novo Mundo, presentes na Carta de Pero Vaz de Caminha lida por um etnógrafo e nos livros que dedica a Cristóvão Colombo, contrapondo-as com as que a etnografia colonial vem posteriormente a fazer das populações ditas primitivas.

Apesar de reformado, Manuel Viegas Guerreiro nunca deixou de ensinar. Ao seu gabinete de trabalho continuaram a afluir mestrandos e doutorandos à procura de orientação e, desejoso de levar o saber universitário a toda a gente, toma a iniciativa de criar os Estudos Gerais Livres - Ensino Público e Gratuito, uma instituição que pretende, de uma forma gratuita, aproximar quem quer ensinar de quem deseja aprender, realizando, desde a sua fundação, em 1988, muitas dezenas de cursos e conferências em Lisboa e noutros locais do país, com um leque de oradores que reúne os maiores especialistas nacionais nas mais diversas áreas do conhecimento. Para tal iniciativa arrasta Agostinho da Silva que proferiu a conferência da sessão inaugural.

Empenhado, desde sempre, na aproximação entre a cultura popular e o meio universitário, foi responsável pela introdução nos curricula universitários, em Portugal e no Brasil, de disciplinas de Literatura Popular Oral e, na sequência do trabalho iniciado com a Linha de Acção de Recolha e Estudo de Literatura Popular, criou em 1993 o Centro de Tradições Populares Portuguesas onde concentrou grande parte da actividade científica dos seus últimos anos. Para além da publicação da Revista Lusitana (Nova Série), da organização de colóquios (Retratos do País e Artes da Fala) e das recolhas de campo, de que é um mestre de referência para as gerações futuras, Manuel Veigas Guerreiro foi coordenador de uma série de projectos, de entre os quais se destaca o seu último grande trabalho, A Ilha de São Jorge: uma monografia.

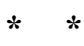

$*$

Não pretendemos fazer, neste breve relato, um historial do contributo do Professor Manuel Viegas Guerreiro para a Antropologia Portuguesa ou do brilhantismo da sua carreira académica. Outros o saberão fazer muito melhor do que nós. Quisemos apenas homenagear um homem que soube olhar os outros como iguais, gostar do que viu e manter esse gosto e curiosidade até ao fim. A grande lição da sua vida está precisamente na disponibilidade para aprender com os outros. Ele próprio escreveu o seu retrato enquanto povo: "O povo de Pitões me ensinou a ser mais directo, mais autêntico, mais o que sou e menos o que me obrigam a ser. Na sua linguagem livre estava o homem livre com que cada um de nós devia reencontrar-se neste mundo de formalidades e disfarces. Esta foi uma das grandes lições que me deu." (Pitões das Júnias, esboço de monografia etnográfica, 1981, p. 13). 